\title{
The Importance of Eosinophilia in The Early Diagnosis of Fascioliasis, Toxocariasis and Hydatidosis
}

\author{
Evren Tileklioglu (Corresponding author) \\ Department of Parasitology, Faculty of Medicine, \\ Aydin Adnan Menderes University, Aydin, Turkey \\ E-mail: etileklioglu@gmail.com \\ Zeynep Tas Cengiz \\ Department of Parasitology, Faculty of Medicine, \\ Van Yuzuncu Yil University, Van, Turkey \\ E-mail: ztas72@hotmail.com \\ The research is financed by Head of Scientific Research Projects at Yuzuncu Yil University \\ (Project No: 2015-SBE-YL262).
}

\begin{abstract}
Helminthiasis, especially in tissue-mediated are the most common cause of persistent eosinophilia. However, these finding neglected and misdiagnosed. This study aims to determine the seroprevalence of fascioliasis, hydatidosis, and toxocariasis in eosinophilic patients and to demonstrate diagnostic criteria of eosinophilia in the early diagnosis of the three parasitic diseases. The study was conducted between March 2015 and June 2016 at the Parasitology Laboratory of Dursun Odabaş Medical Center at Yuzuncu Yil University, Van, Turkey. The eosinophilic group included 270 cases and the control group included 100 non eosinophilic cases. Blood samples from both eosinophilic cases and the control cases were analyzed by ELISA method. The eosinophilic group were determined $11.5 \%$ seropositive for fascioliasis, $7 \%$ for hydatidosis and $15.2 \%$ were seropositive for toxocariasis. The control group seropositivity was determined as $4 \%$ for fascioliasis, $5 \%$ for hydatidosis and $7 \%$ for toxocariasis. All of the cases, who were identified as seropositive, were found positive for only one of these diseases. Significant differences were determined between eosinophilia and Fasciola hepatica $(\mathrm{p}<0.05)$ and Toxocara sp. $(\mathrm{p}<0.05)$ seropositivity. No significant difference was determined for the frequency of parasite prevalence among these three groups of cases between age groups (except for cases with positive hydatidosis $(\mathrm{p}<0.05)$ ) and gender. As a result, it is concluded that evaluating the eosinophilic cases serologically for fascioliasis and toxocariasis could be useful for definitive diagnosis.
\end{abstract}

Keywords: Eosinophilia, Fascioliasis, Hydatidosis, Toxocariasis

DOI: $10.7176 / \mathrm{JHMN} / 78-01$

\section{Introduction}

The developmental stage of parasite infections in mammals leads to discrete many immune responses. Eosinophils, are important effector cells in the host responses against several important disorders, such as allergic diseases, cancer, and parasitic diseases. Many researchers focus on the relationship between increased eosinophilia and parasitic diseases mainly helminthic diseases. (Dombrowicz \& Capron 2001; Kovalszki \& Weller 2016).

Nowadays, the prevalence and significance of human fascioliasis, an infection due to a zoonotic liver fluke by the Fasciola hepatica (F. hepatica), increased the development of diagnostic methods. The disease is characterized by clinically many prognoses including asymptomatic infections, severe cirrhosis, and even mortality. However, this disease is often characterized by fever, abdominal pain, and eosinophilia. (Furst et al. 2012; Khademvatan et al. 2019; Mas-Coma et al. 2005).

Hydatidosis caused by the larval form of Echinococcus granulosus can be life-threatening and nonspecific clinic signs. The symptoms begin to emerge as the cysts caused by the parasites grow and pressure of cysts on the surrounding organs or as complications increase, after an incubation period (Elmajdoub et al. 2015; Hijjawi et al. 2018; Possenti et al. 2016). In many studies reported that eosinophils contribute to host defenses against the hydatidosis (Ferreira et al. 2000).

Visceral larva migration (VLM), caused by the larvae of Toxocara sp., characterized mild symptoms in

1 I $\mathrm{P}$ a g e

www.iiste.org 
adults, while severe symptoms in young children. As the larvae can settle in all organs of the body and can be migrated in the eye which is recognized ocular larva migrans. The infection is characterized by hypereosinophilia, hepatomegaly, fever, transient pulmonary infiltration symptoms, and hypergammaglobulinemia (Kim et al. 2014; Overgaauw 1997; Selek et al. 2016).

This study aims to determine the seroprevalence of fascioliasis, toxocariasis, and hydatidosis in eosinophilic cases and to demonstrate the importance of eosinophilia in the early diagnosis of the three parasitic diseases.

\section{Material and Methods}

The study was conducted between March 2015, and June 2016, at the Parasitology Laboratory of Dursun Odabaş Medical Center in Yuzuncu Yil University, Van/Turkey. All of the cases included who applied the internal medicine polyclinic. The biochemistry and hematological parameters of the blood samples taken from the patients admitted to the internal medicine polyclinic was followed. Blood samples of eosinophilic and non-eosinophilic cases were kept for study at $-20{ }^{\circ} \mathrm{C}$.

Blood samples from both the eosinophilic cases and the control group were analyzed by the ELISA method according to the manufacturer's instructions. The ELISA method were analyzed for F.hepatica which is the highest sensitivity (100\%) and specificity (100\%) (DRG International, Inc., USA; IgG), hydatidosis sp. (R-Biopharm, Germany; IgG) which is the sensitivity $(93,8 \%)$ and specificity $(90,6 \%)$ and Toxocara sp. (R-Biopharm, Germany; $\mathrm{IgG}$ ) which is the sensitivity $(100 \%)$ and specificity $(90,7 \%)$ separately. Primarily, the ethics committee approval report was obtained from the Scientific Research Ethics Committee of the Faculty of Medicine at Yuzuncu Yil University.

Statistical analysis

Descriptive statistics for the categorical variables were presented as count and percent. The chi-square test was calculated for determining relationships between the categorical variables. $\mathrm{Z}$ test was also used for comparison of proportions. Descriptive statistics for the studied variables (characteristics) were presented as mean, standard deviation, minimum and maximum values. Statistical significance level was considered as 5\% and SPSS (ver: 13) statistical program was used for all statistical computations.

\section{Results}

In present study, a total of 270 cases were eosinophilic, 147 were female and 123 were male. The control group which is non-eosinophilic group was composed of 55 were female and 45 were male. Mean and standard deviation of eosinophil percentage were determined as 9,41 $\pm 6,12$ (min-max: 5,153,8 ) in the eosinophilic group and were 3,29 $\pm 1,03$ (min-max: 1,1-4,9) in the control group.

The eosinophilic cases were composed of 106 youngers than the age of 35, 164 cases older than or equal to the age of 36 (for age, mean $(\mathrm{m}) \pm$ standard deviation $(\mathrm{sd})$ : 44,34 $\pm 17,97$, minimum (min) maximum ( $\max$ ): 18-90). The control group was composed of 39 cases younger than the age of 35, 61 cases older than or equal to the age of 36 (for age, $\mathrm{m} \pm \mathrm{sd}$ : 41,48 $\pm 14,28$; min-max: 18-73).

Eosinophilic and control group age averages were calculated as 44,55 $\pm 18,22$ (min-max: 19-78) and $40,0 \pm 12,36$ (min-max: 23-52) in fascioliasis seropositive cases, 52,89 $\pm 17,6$ (min-max: 20-85) and $47,8 \pm 12,72$ (min-max: 30-60) in hydatidosis seropositive cases, and 44,12 $\pm 15,06$ (min-max: 20-77) and 37,29 $\pm 13,4$ (min-max: 19-57) in toxocariasis seropositive cases, respectively.

Of the 270 eosinophilic cases, $11.5 \%$ were found seropositive for fascioliasis, $7 \%$ for hydatidosis, and $15.2 \%$ were found seropositive for toxocariasis. For the control group composed of 100 cases, seropositivity was determined as $4 \%$ for fascioliasis, $5 \%$ for hydatidosis and $7 \%$ for toxocariasis.

All of the cases, who were determined as seropositive, were found positive for only one of these diseases (Table 1, Table 2). Blood samples from the cases who exhibit two or three co-positivity for these three parameters were not included in the study.

Seropositivity of the three parasitic agents in eosinophilic cases and the seropositivity in the control group composed of healthy and non-eosinophilic individuals were separately compared statistically; significant differences were determined between eosinophilia and $F$. hepatica $(\mathrm{p}<0.05)$ and Toxocara $\mathrm{sp} . \quad(\mathrm{p}<0.05)$ seropositivity. No significant difference was determined for the frequency of parasite prevalence among these three groups of cases between age groups (except for cases with positive hydatidosis $(p<0.05)$ ) and gender (Table 1, Table 2). For all three of the diseases, seropositivity was determined highest in cases with an eosinophil percentage of 5 to 10 (Table 3). 
Table 1. Seropositivity of fascioliasis, hydatidosis and toxocariasis in patient group according to age groups and gender

\begin{tabular}{|c|c|c|c|c|c|c|c|c|c|c|}
\hline \multirow[t]{2}{*}{ Parameters } & \multicolumn{2}{|c|}{$\begin{array}{c}\text { Total } \\
(\mathrm{N}: 270)\end{array}$} & \multicolumn{2}{|c|}{$\begin{array}{c}\leq \mathbf{3 5} \text { years } \\
(\mathrm{N}: 106)\end{array}$} & \multicolumn{2}{|c|}{$\begin{array}{c}\geq \mathbf{3 6} \text { years } \\
(\mathrm{N}: 164)\end{array}$} & \multicolumn{2}{|c|}{$\begin{array}{l}\text { Female } \\
(\mathrm{N}: 147)\end{array}$} & \multicolumn{2}{|c|}{$\begin{array}{c}\text { Male } \\
(\mathrm{N}: 123)\end{array}$} \\
\hline & $\mathrm{n}$ & $\%$ & $\mathrm{n}$ & $\%$ & $\mathrm{n}$ & $\%$ & $\mathrm{n}$ & $\%$ & $\mathrm{n}$ & $\%$ \\
\hline Fascioliasis (N: 270) & $31 *$ & 11.5 & 11 & 10,4 & 20 & 12,2 & 18 & 12,2 & 13 & 10,6 \\
\hline Hydatidosis (N: 270) & 19 & 7 & $3 * *$ & 2,8 & 16 & 9,8 & 12 & 8,2 & 7 & 5,7 \\
\hline Toxocariasis (N: 270) & $41 *$ & 15,2 & 16 & 15,1 & 25 & 15,2 & 20 & 13 & 21 & 17,1 \\
\hline
\end{tabular}

$\mathrm{N}$ : Total number of patients, n: Positive patients,

* Those found significant when compared to the control group $(\mathrm{p}<0.05)$

** Those found significant in the comparison between age groups $(\mathrm{p}<0.05)$

Table 2. Seropositivity of fascioliasis, hydatidosis and toxocariasis in control group according to the age groups and gender

\begin{tabular}{|c|c|c|c|c|c|c|c|c|c|c|}
\hline \multirow[t]{2}{*}{ Parameters } & \multicolumn{2}{|c|}{$\begin{array}{c}\text { Total } \\
\text { (N: 100) }\end{array}$} & \multicolumn{2}{|c|}{$\begin{array}{c}\leq \mathbf{3 5} \text { years } \\
(\mathrm{N}: 39)\end{array}$} & \multicolumn{2}{|c|}{$\begin{array}{c}\geq 36 \text { years } \\
(\mathrm{N}: 61)\end{array}$} & \multicolumn{2}{|c|}{$\begin{array}{l}\text { Female } \\
(\mathrm{N}: 55)\end{array}$} & \multicolumn{2}{|c|}{$\begin{array}{c}\text { Male } \\
(\mathrm{N}: 45)\end{array}$} \\
\hline & $\mathrm{n}$ & $\%$ & $\mathrm{n}$ & $\%$ & $\mathrm{n}$ & $\%$ & $\mathrm{n}$ & $\%$ & $\mathrm{n}$ & $\%$ \\
\hline Fascioliasis (N: 100) & 4 & 4 & 1 & 2,6 & 3 & 4,9 & 3 & 5,5 & 1 & 2,2 \\
\hline Hydatidosis (N: 100) & 5 & 5 & 1 & 2,6 & 4 & 6,6 & 3 & 5,5 & 2 & 4,4 \\
\hline Toxocariasis (N: 100) & 7 & 7 & 3 & 7,8 & 4 & 6,6 & 4 & 7,3 & 3 & 6,7 \\
\hline
\end{tabular}

$\mathrm{N}$ : Total number of patients, $\mathrm{n}$ : Positive patients

Table 3. Positivity values according to the percentage range of eosinophil in the patient group

\begin{tabular}{lcccccc}
\hline & \multicolumn{2}{c}{ Eosinophil 5-10\% } & Eosinophil 10-20\% & \multicolumn{2}{c}{ Eosinophil 20\% $\geq$} \\
\cline { 2 - 7 } Parameters & $\mathbf{n}$ & $\%$ & $\mathbf{n}$ & $\%$ & $\mathbf{n}$ & $\%$ \\
\hline Fascioliasis (n: 31) & 16 & 51,6 & 12 & 38,7 & 3 & 9,7 \\
\hline Hydatidosis (n: 19) & 17 & 89,5 & 2 & 10,5 & 0 & 0 \\
\hline Toxocariasis (n: 41) & 26 & 63,4 & 11 & 26,8 & 4 & 9,8 \\
\hline
\end{tabular}

$\mathrm{n}$ : Positive patients 


\section{Discussion}

It was reported that the increase in peripheral eosinophil count could occur due to parasitic infections besides various factors such as infectious diseases, malignant or allergic diseases. Many reports published that the eosinophilia was an important finding in parasitic infections, especially in tissuemediated helminthiases such as fascioliasis, hydatidosis, and toxocariasis. Numerous studies have been carried out the relationship between these parasitic infections and eosinophilia (Klion \& Nutman 2004). Serologic studies are the main diagnostic methods which is rapid, sensitive and quantitative, used and permit diagnosis of many helminth infections such as fascioliasis, hydatidosis and toxocariasis. Although ELISA has been reported to be a sensitive test (specificity 95-100\% and sensitivity 90 $100 \%$ ), cross reactions have been described for antibodies against other parasites. (Ishida et al. 2003; Romasanta et al 2003). The test used in this study reported that fascioliasis and toxocariasis do not have multiple infections other parasites due to sensitivity and specificity. Cross-reactions for antibodies to Taenia solium have been described in the test used for hydatidosis.

In published reports from different countries and Turkey, to determine the range of the relationship between seropositivity of F.hepatica and eosinophilia. In some of the studies, fascioliasis positivity was investigated directly in patients with eosinophilia. In such framework, (el-Shabrawi et al. 1997) determined positivity for this parasitosis in 13 of the 16 child patients with eosinophilia, Demirci et al., (2003) reported that $6,1 \%$ of those who are eosinophilic and $0.9 \%$ of those who are non-eosinophilic (Demirci et al. 2003), and Demirci et al. (2002) determined positivity for this parasitosis in $8,9 \%$ of those who are eosinophilic, in 3,7\% of those who are non-eosinophilic, and in $1,2 \%$ of the control group (Demirci et al. 2002). In present study, fascioliasis positivity was determined in $11,5 \%$ of the 270 cases with eosinophilia and a statistically significant difference $(p<0.05)$ was found between the positivity of this parasitosis and eosinophilia.

Our province is located in Turkey's Eastern Anatolia region. In previous studies, it has been reported that fascioliasis is determined in both animals and humans (Denizhan 2018; Karahocagil et al. 2011; Yilmaz \& Godekmerdan 2004). In our study, blood samples from the cases who exhibit two or three co-positivity parameters were not included in the study, considering the possibility of cross-reactions. The control group seropositivity was determined as $4 \%$ for fascioliasis. The reason for this, crossreactions may be found low seropositivity value another helminthic infections or in chronic phase for $F$. hepatica have settled into the bile ducts and peripheral eosinophilia is not a finding in the acute stage (Al Qurashi et al. 2012). A study report that, 101 chronic cases from the Andean region and many endemic areas: 48\% had eosinophilia above normal levels (Alban et al, 2002). According to the studies, it did not become certain whether there exists any difference between genders for the prevalence of fascioliasis (Khademvatan et al. 2019). In one of the studies, it was reported that parasitosis were more frequent in females and statistically significant differences were observed between genders (Tas Cengiz et al. 2015). In a study, it was stated that the results presented no statistically significant differences between genders, parallel to the results of this study (Demirci et al. 2003). In one of the above-stated studies (Tas Cengiz et al. 2015) on the prevalence of fascioliasis, age groups were compared for the parasite prevalence and statistical significance was determined in contrast to our study.

The prevalence of VLM was investigated serologically in the eosinophilic patients and various findings were obtained. Çiçek \& Y 1 lmaz (2012) reported this parasitosis in 28,5\% of the 200 eosinophilic patients (Çiçek \& Y 1 lmaz 2012), 10,83\% of the 600 non-eosinophilic individuals, Yaman Karadam et al. (2009) in $32,6 \%$ of the 350 eosinophilic and $20,3 \%$ of the 350 non-eosinophilic individuals (Karadam et al. 2009), and Demirci et al. (2002) reported this parasitosis in $29,1 \%$ of the 134 eosinophilic patients, $19,4 \%$ of the 134 non-eosinophilic individuals, and $15,5 \%$ of the control group composed of 84 individuals (Demirci et al. 2002). In present study, Toxocara sp., positivity was determined in $15,2 \%$ of the 270 eosinophilic cases. The statistical evaluation demonstrated a significant $(p<0.05)$ relationship between parasitosis positivity and eosinophilia. This result presented similarities with the findings of the three studies mentioned above. (Çiçek \& Y1lmaz 2012; Demirci et al. 2002; Karadam et al. 2009; Tas Cengiz et al. 2015)

The control group seropositivity was determined as $7 \%$ for toxocariasis in our study. For this reason, as stated in the review that the spontaneous decrease in the number of eosinophils may be related to when migration of the larval form ceases and the infection becomes patent (Klion et al. 2004). Also, in a study reported that there was a significant difference between the fixation and migration of the lunginvolved toxocariasis in patients with and without eosinophilia (Park et al. 2014)

Toxocariasis is known to be more prevalent in children than in adults. (McGuinness \& Leder 2014) Two studies (Çiçek \& Yılmaz 2012; Karadam et al. 2009) revealed statistically significant relationships between age groups in terms of the prevalence of parasitosis. The difference between genders and toxocariasis positivity exhibited no significance in one of the studies; in others, gender-based ratio

4 I $\mathrm{P}$ a g e

www.iiste.org 
information was provided or no statistical comparison was conducted (Çiçek \& Y1lmaz 2012). In our study, no significant differences were found between age groups and genders for toxocariasis positivity. Many studies focus on the relationship between hydatidosis and eosinophilia. In a study, hydatidosis positivity was determined in 23 of 2198 patients, (Singer et al. 2013) another, the positivity of hydatidosis was determined as $0,53 \%$ for 946 patients (Karadam et al. 2009). In our study, $7 \%$ of seropositivity was determined in the 270 eosinophilic cases, while 5\% was determined in the 100 healthy and non-eosinophilic individuals (control group), but no statistically significant difference between the groups were identified.

In our control group positivity may be related to two reasons. The first, cyst rupture which is causes often iatrogenic eosinophil counts are transiently suppressed as highlighted in a study (Sekiguchi et al. 2013). The second, in addition to the control and the eosinophilic group, cross reactions have been described for antibodies against another helminth (Poretti et al. 1999). We think that more studies should be done on this subject.

Although it is reported that young individuals are more susceptible to cystic hydatidosis comparison to older persons, different results, concerning this subject, were obtained in the studies (Eckert \& Deplazes 2004). In a study, it was reported that this parasitosis was more resident in patients between the ages of 30 and 39 (Montúfar-Valer \& Huapaya-Jurado 2014) and another, it was found more prevalent in patients over 40 years of age and statistically significant difference between the age groups was determined in terms of positivity (Güreser et al. 2015). In present study, positivity was determined at a higher rate in eosinophilic cases in the group of 36 and higher years of age and a statistically significant difference $(\mathrm{p}<0.05)$ was obtained between age groups for the positivity of the parasite. It was observed that gender group comparisons were not conducted for positivity of hydatidosis or no statistically significant difference was determined between the groups in the related studies (Güreser et al. 2015). No statistically significant difference between the genders in terms of positivity was identified in present study.

Clinical and laboratory diagnosis of fascioliasis, hydatidosis and toxocariasis is quite difficult since it requires both experienced staff and expensive methods. Besides the diagnostic difficulties of the parasitosis, diagnosis is more complicated when the cases present non-specific clinical symptoms. Therefore, it was evaluated in many studies, lead to today, that it is essential to consider several criteria such as eosinophilia in the approach towards the cases. As the findings obtained in present study are considered, statistically significant relationships between fascioliasis and toxocariasis and eosinophilia were separately determined, but no significant relationship between hydatidosis and eosinophilia was confirmed.

\section{Conclusion}

As a result of this, while study is considered, it is realized that there exists a relationship between eosinophilia and fascioliasis and toxocariasis. As a result, it is concluded that evaluating the eosinophilic cases serologically for fascioliasis and toxocariasis could be useful for definitive diagnosis.

\section{Conflict of Interest statement}

No conflict of interest was declared by the authors.

\section{Annotation}

This article is the shorter version of the master's thesis entitled. 'Seroprevalence of fascioliasis, toxocariasis, and hydatidosis in eosinophilic patients'

\section{Acknowledgement}

We would like to thank Head of Scientific Research Projects at Yuzuncu Yil University for supporting this research (Project No: 2015-SBE-YL262). We also thank Professor Siddik Keskin for his kind contribution to the statistical analysis.

\section{References}

Al Qurashi H, Masoodi I, Al Sofiyani M, Al Musharaf H, Shaqhan M, All GNAA (2012). Biliary fascioliasis-an uncommon cause of recurrent biliary colics: Report of a case and brief review. GMS Ger Medical Sci 10. doi: 10.3205/000161 
Albán Olaya, M, Jave Ortiz, J, Quispe Lazo T (2002). fasciolasis en Cajamarca. Rev Gastroenterol Peru 22, 28-32.

Çiçek M, Yılmaz H (2012). Prevalence of Toxocariasis in Human and Dogs in Van Province. Kafkas Univ Vet Fak 18, 531-536. doi:10.9775/kvfd.2011.5211.

Demirci M, Korkmaz M, Kaya S, Kuman A (2003). Fascioliasis in eosinophilic patients in the Isparta region of Turkey. Infection 31,15-18. doi:10.1007/s15010-002-3089-7.

Demirci M, Korkmaz M, Sakru N, Kaya S, Kuman A (2002) Diagnostic importance of serological methods and eosinophilia in tissue parasites. J Health Popul Nutr 20, 352-355. doi: 10.3329/jhpn.v20i4.175.

Denizhan V (2018). Seroprevalence of Fasciola hepatica in Sheep in the Province of Van and Some Districts. Atatürk Üniversitesi Vet. Bil. Derg 13,278-284. doi: 10.17094/ataunivbd.500867.

Dombrowicz D, Capron M (2001). Eosinophils, allergy and parasites. Curr Opin Immunol 13,716720. doi: 10.1016/s0952-7915(01)00284-9.

Eckert J, Deplazes P (2004). Biological, epidemiological, and clinical aspects of echinococcosis, a zoonosis of increasing concern. Clin Microbiol Rev 17,107-135. doi: 10.1128/cmr.17.1.107135.2004 .

el-Shabrawi M, el-Karaksy H, Okasha S, el-Hennawy A (1997). Human fascioliasis: clinical features and diagnostic difficulties in Egyptian children. $J$ Trop Pediatr 43,162-166. doi:10.1093/tropej/43.3.162.

Elmajdoub L, Wa R, Sam N, Wajidi M (2015). Present Status on the Taxonomy and Morphology of Echinococcus Granulosus: A Review. Austin J Vet Sci \& Anim Husb 2,1-6.

Ferreira AM, Breijo M, Sim RB, Nieto A (2000). Contribution of C5-mediated mechanisms to host defence against Echinococcus granulosus hydatid infection. Parasite Immunol 22, 445-53. doi: 10.1046/j.1365-3024.2000.00323.x.

Furst T, Keiser J, Utzinger J (2012). Global burden of human food-borne trematodiasis: a systematic review and meta-analysis. Lancet Infect Dis 12,210-221. doi:10.1016/S14733099(11)70294-8.

Güreser AS, Özcan O, Özünel L, Boyacıŏlu Zİ, Taylan Özkan HA (2015). Evaluation of the Radiological, Biochemical and Serological Parameters of Patients Prediagnosed as Cystic Echinococcosis in Çorum, Turkey. Mikrobiyol Bul 49, 231-239. doi: 10.5578/mb.8656.

Hijjawi NS, Al-Radaideh AM, Rababah EM, Al-Qaoud KM, Bani-Hani KE (2018). Cystic echinococcosis in Jordan: a review of causative species, previous studies, serological and radiological diagnosis. Acta tropica 179,10-16. doi: 10.1016/j.actatropica.2017.12.017.

Ishida MMI, Rubinsky-Elefant G, Ferreira AW, Hoshino-Shimizu S, Vaz AJ (2003). Helminth antigens (Taenia solium, Taenia crassiceps, Toxocara canis, Schistosoma mansoni and Echinococcus granulosus) and cross-reactivities in human infections and immunized animals. Acta tropica 89,73-84. doi:10.1016/j.actatropica.2003.09.005.

Karadam SY, Ertabaklar H, Sari C, Dayanir Y, Ertuğ S (2009). Should cystic echinococcosis be investigated in patients having high eosinophil counts?. Turkiye Parazitol derg 33,203-206.

Karahocagil MK, Akdeniz H, Sunnetcioglu M, Cicek M, Mete R, Akman N, Ceylan E, Karsen H, Yapici K (2011). A familial outbreak of fascioliasis in Eastern Anatolia: a report with review of literature. Acta Trop 118,177-183. doi:10.1016/j.actatropica.2008.08.013.

Khademvatan S, Majidiani H, Khalkhali H, Taghipour A, Asadi N, Yousefi E (2019). Prevalence of fasciolosis in livestock and humans: A systematic review and meta-analysis in Iran. Comp Immunol Microb 65,116-123. https://doi.org/10.1016/j.cimid.2019.05.001. 
Kim HS et al (2014). Significance of serum antibody test for toxocariasis in healthy healthcare examinees with eosinophilia in Seoul and Gyeongsangnam-do, Korea. J Korean Med Sci 29,1618-1625. doi:10.3346/jkms.2014.29.12.1618.

Klion AD, Nutman TB (2004). The role of eosinophils in host defense against helminth parasites. $J$ Allergy Clin Immunol 113,30-37. doi:10.1016/j.jaci.2003.10.050.

Kovalszki A, Weller PF (2016). Eosinophilia. Primary Care: Clinics in Office Practice 43,607-617. https://doi.org/10.1016/j.pop.2016.07.010.

Mas-Coma S, Bargues MD, Valero MA (2005). Fascioliasis and other plant-borne trematode zoonoses. Int J Parasitol 35,1255-1278. doi:10.1016/j.ijpara.2005.07.010.

McGuinness SL, Leder K (2014). Global burden of toxocariasis: a common neglected infection of poverty. Curr Trop Med Rep 1,52-61. doi: 10.1007/s40475-013-0012-5.

Montúfar-Valer A, Huapaya-Jurado F (2014). Clinical, radiological and laboratory features of liver hydatidosis of patients from a hospital of national reference, Lima 1997-2010. Rev Gastroenterol Peru 34,203-209.

Overgaauw PA (1997). Aspects of Toxocara epidemiology: human toxocarosis. Crit Rev Microbiol 23,215-231. doi:10.3109/10408419709115137.

Park BM, Jeong SO, Park HS, Jung SS, Kim SY, Kim JO, Lee JE (2014). Differences in the clinical and radiological characteristics of lung-involved toxocariasis between toxocariasis with eosinophilia and those without eosinophilia. $J$ Thorac Dis 6, 1757-1764. doi: 10.3978/j.issn.2072-1439.2014.12.24.

Poretti D, Felleisen E, Grimm F, Pfister M, Teuscher F, Zuercher C, Gottstein B (1999). Differential immunodiagnosis between cystic hydatid disease and other cross-reactive pathologies. Am J Trop Med Hyg 60,193-198. doi: 10.4269/ajtmh.1999.60.193.

Possenti A, Manzano-Roman R, Sanchez-Ovejero C, Boufana B, La Torre G, Siles-Lucas M, Casulli A (2016). Potential risk factors associated with human cystic echinococcosis: systematic review and meta-analysis. Plos Neglect Trop D 11, e0005801. https://doi.org/10.1371/journal.pntd.0005114.

Romasanta A, Romero JL, Arias M, Sánchez-Andrade R, López C, Suárez JL, Paz-Silva A (2003). Diagnosis of Parasitic Zoonoses by Immunoenzymatic Assays-Analysis of Cross-Reactivity Among the Excretory/Secretory Antigens of Fasciola hepatica, Toxocara canis, and Ascaris suum. Immunol Invest 32, 131-142. doi:10.1081/IMM-120022974.

Sekiguchi H, Suzuki J, Pritt BS, Ryu JH (2013). Coughing up a diagnosis: a cavitary lung lesion with worsening eosinophilia. Am J Med 126,297-300. doi: 10.1016/j.amjmed.2012.12.004.

Selek MB, Karagoz E, Baylan O (2016). Toxocariasis: a review. Medicine Science 5,1063-1067. doi: $10.5455 /$ medscience.2016.05.8471.

Singer C, Stancu P, Coşoveanu S, Botu A, Cristea C, Baciu D (2013). Study on the frequency and values of sanguine eosinophilia in children admitted with parasitary diseases. Curr health Sci J 39,93-96.

Tas Cengiz Z, Yilmaz H, Dulger AC, Akdeniz H, Karahocagil MK, Cicek M (2015). Seroprevalence of human fascioliasis in Van province, Turkey. Turk $J$ Gastroenterol 26,259-262. doi:10.5152/tjg.2015.8001.

Yilmaz H, Godekmerdan A (2004). Human fasciolosis in Van province, Turkey. Acta Trop 92,161162. doi:10.1016/j.actatropica.2004.04.009 